\title{
The Effects of Cannabinoid System on Acute Lung Injury Induced by Mesenteric Ischemia/Reperfusion in Rats
}

\author{
Emine Yilmaz Can ${ }^{1 *}$, Kanat Gulle ${ }^{2}$, Meryem Akpolat Ferah ${ }^{3}$, Murat Can ${ }^{4}$, Berrak Guven ${ }^{4}$, Firuzan Kokturk ${ }^{5}$ and \\ Burcu Karauzum ${ }^{6}$
}

${ }^{1}$ Department of Medical Pharmacology, Zonguldak Bulent Ecevit University, Turkey

${ }^{2}$ Department of Histology, Suleyman Demirel University, Turkey

${ }^{3}$ Department of Histology, Zonguldak Bulent Ecevit University, Turkey

${ }^{4}$ Department of Biochemistry, Zonguldak Bulent Ecevit University, Turkey

${ }^{5}$ Department of Biostatistics, Zonguldak Bulent Ecevit University, Turkey

${ }^{6}$ Ministry of Health, Ankara, Turkey

Submission: September 15, 2021; Published: September 30, 2021

*Corresponding author: Emine Yilmaz-Can, MD, Zonguldak Bulent Ecevit University, Faculty of Medicine, Department of Medical Pharmacology, 67600 Kozlu, Zonguldak, TURKEY

\section{Abstract}

Background: Cannabinoids are considered as key mediators in the pathophysiology of inflammatory diseases, including ischemia/reperfusion (I/R). However, there is no detailed information about the effects of cannabinoids on acute lung injury induced by mesenteric I/R in rats. The aim of this study is to investigate for the first time the possible effects of cannabinoid system on pathophysiological changes of acute lung injury induced by mesenteric $\mathrm{I} / \mathrm{R}$ in rats.

Materials and Methods: The superior mesenteric artery was blocked for $30 \mathrm{~min}$ followed by $24 \mathrm{~h}$ of reperfusion. Selective monoacylglycerol lipase inhibitor; JZL184, non selective cannabinoid receptor agonist; cannabidiol and selective CB2 agonist; JWH133 were administered to rats $30 \mathrm{~min}$ before ischemia. At the end of the $24 \mathrm{~h}$ reperfusion period, intestinal and lung tissues were removed; caspase 3, 8, 9 immunohistochemistry staining, caspase- 3 activity and malondialdehyde (MDA) levels were evaluated. Serum IL-1, TNF- $\alpha$, IL-6 levels and total antioxidant capacity (TAC) also measured.

Results: In intestine tissue; decrease in intestinal mucosal damage was detected with all three therapeutic agents but it was not statistically significant. Cannabidiol and JZL184 significantly reduced caspase 3, 8 and 9 immunohistochemical staining. In lung tissue; Cannabidiol significantly reduced caspase 3, 8 and 9 immunohistochemical staining while JZL184 significantly reduced caspase 8 staining. JZL184 significantly reduced alveolar congestion, haemorrhage, neutrophilic infiltration and alveolar wall thickening while JWH133 significantly reduced neutrophilic infiltration and alveolar wall thickness. No significant differences were observed in terms of biochemical parameters in the control and ischemiareperfusion groups.

Conclusion: This study has shown that the cannabinoid system may be a therapeutic target for attenuation and/or treatment of inflammatory lung diseases induced by mesenteric I/R

Keywords: Acute lung injury; Cannabinoids; JLZ184; JWH133; Mesenteric ischemia reperfusion

Abbreviations: I/R: Ischemia/Reperfusion; MDA: Malondialdehyde; TAC: Total Antioxidant Capacity; IL-1ß: Interleukin 1beta ; TNF- $\alpha$ : Tumor Necrosis Factor-Alpha ; IL-6: Interleukin 6 ; ROS: Reactive Oxygen Species; RNS: Reactive Nitrogen Species; ARDS: Acute Respiratory Distress Syndrome; CB: Cannabinoid; CB1: Cannabinoid Receptor 1; CB2: Cannabinoid Receptor 2; THC: Delta-9 Tetrahydrocannabinol; CBD: Cannabidiol; ALI: Acute Lung Injury; MAGL: Monoacylglycerol Lipase; ABC: Avidin-Biotin Complex; PBS: Phosphate Buffered Saline; TBA: Thiobarbituric Acid; BSA: Bovine Serum Albumin

\section{Introduction}

Ischemia and subsequent reperfusion are the main mechanism that causes end organ damage that complicates the course of the disease in pathologies such as circulatory shock, organ transplantation, myocardial infarction, and stroke. The common pathological consequence in these conditions is that 
reperfusion after temporary cessation of normal blood supply to target organs induces an acute generation of reactive oxygen and nitrogen species following reoxygenation with vascular reopening. As a result of all these changes, a highly deleterious cellular response chain is activated, leading to inflammation, cell death, and target organ dysfunction or failure [1,2].

Intestinal ischemia/reperfusion (I/R) injury is thought to be a causative mechanism for several gastrointestinal diseases, such as necrotizing enterocolitis and mesenteric insufficiency in the elderly, as well as intestinal dysfunction following bowel transplantation. I/R is a complex phenomenon that causes local and remote tissue destruction and even multiple-organ failure $[1,2]$. Multiple-organ failure after serious illness or injury is a major cause of death in surgical intensive care unit, and the exact pathophysiology and adequate treatment of this syndrome is still unclear. Remote organ injuries seen after intestinal I/R are not directly because of exogenous factors such as bacteria or toxins, are largely a consequence of the host's own endogenously produced mediators, such as reactive oxygen species (ROS), reactive nitrogen species (RNS) and cytokines [3-5]. These mediators interact with each other and are involved in multipleorgan failure syndrome especially in aged patients.

Severe intestinal I/R is accompanied by significant pulmonary injury and systemic inflammatory changes. The pulmonary system is the most frequently injured organ in multiorgan disorder syndrome. Subsequent to $I / R$, pulmonary injury may rapidly progress to respiratory failure and acute respiratory distress syndrome (ARDS). ARDS is a life-threatening form of respiratory failure that affects approximately 200000 patients each year in the United States, resulting in nearly 75000 deaths annually. Globally, ARDS accounts for $10 \%$ of intensive care unit admissions, representing more than 3 million patients with ARDS annually [6]. The events which occur during I/R and remote organ injury are complex and well studied, although, there still remain many doubts as to their pathophysiology and therapeutics, revealing the need for new research to obtain a more complete understanding and in the search for improved treatments.

Overwhelming clinical evidence has established an important role for cannabinoids (CB) in various pathologies affecting humans, i.e., inflammatory, autoimmune, cardiovascular, gastrointestinal, liver, kidney, lung, neurodegenerative and psychiatric diseases, chronic pain and cancer [7-13]. In recent years, in the light of these results, clinical studies are planned to investigate the efficacy and safety of phytocannabinoids in certain diseases [13]. However, the use of cannabinoids is limited in modern medicine because of its neuropsychiatric side effects. Cannabinoid receptor 1 (CB1) and cannabinoid receptor 2 (CB2), central and peripheral effects and side effects of the cannabinoid system began to be determined in more detail after isolation of the active ingredient delta-9 tetrahydrocannabinol (THC) $[13,14]$. Delta-9 tetrahydrocannabinol and cannabidiol (CBD) are the most important phytocannabinoids. THC is the main psychoactive compound, while CBD is devoid of psychotropic activity [14].

CBD is assumed to be used more safely because it is now widely available and lacks the euphoric, psychoactive properties of THC. Cannabis sativa is a substance used for centuries to treat gastrointestinal diseases such as inflammatory bowel diseases, anorexia, motility disorders, diarrhea, gastroparesis, vomiting and abdominal pain $[15,16]$. However, neuropsychiatric side effects limit its use in modern medicine and the expected increase in advanced clinical research. In the literature, it is observed that we do not have sufficient knowledge for cannabinoids about the gastrointestinal tract diseases and associated distant organ damages. In particular, there is no enough information about the effects of cannabinoids on acute lung injury (ALI) induced by mesenteric I/R.

The aim of this study is to investigate the effects of non selective cannabinoid receptor agonists (CB1 and CB2 receptors); cannabidiol, selective monoacylglycerol lipase (MAGL) inhibitor; JZL184, and selective CB2 agonist; JWH133, on previously unexamined mesenteric 30min/24h I/R-induced remote organ injury.

\section{Materials and Methods}

\section{Animals}

Adult male Wistar Albino rats weighing 250-280 were employed in the present study obtained from the animal laboratory of Zonguldak Bulent Ecevit University. They were kept under controlled conditions (at temperature of $22 \pm 2^{\circ} \mathrm{C}$ and $12 \mathrm{~h}$ light-dark cycles) and were fed with rat chow diet and tap water. Rats were fasted prior to operation and were allowed just free access to water. The experimental protocols were confirmed by the Bulent Ecevit University of Ethical Committee of Experimental Animals. During the experimental procedures, the animals were placed in separate cages and the laboratory conditions were maintained at room temperature $\left(22^{\circ} \mathrm{C}\right)$. The procedures and protocols of the study were in accord with our institutional guidelines, which are consistent with those of the "Guide for the Care and Use of Laboratory Animals" (US National Institute of Health, revised 1985).

\section{Experimental groups}

Fifty rats were designed into five groups each containing 10 animals (Table 1): 1) Control group, 2) I/R group, 3) Non selective cannabinoid receptor agonist, cannabidiol $(10 \mathrm{mg} / \mathrm{kg})$ treatment group (expressed as CD), 4) Selective CB2 receptor agonist; JWH133 (10mg/kg) treatment group (expressed as B2), and 5) Selective monoacylglycerol lipase (MAGL) inhibitor; JZL184 (8mg/ kg) treatment group (expressed as MA). Cannabidiol, JWH133, and JZL184 treatments were administered intraperitoneally $30 \mathrm{~min}$ before ischemia. Animals in control and I/R groups were received equal volume of saline (Table 1 ). 
Table 1: Experimental Groups $(n=10)$.

\begin{tabular}{|c|c|c|}
\hline \multirow{2}{*}{ Groups } & Chemicals & \multirow{2}{*}{} \\
\hline 1 & Control & \\
\hline 2 & $\mathrm{I} / \mathrm{R}$ Pathology group & \\
\hline 3 & $\mathrm{I} / \mathrm{R}+\mathrm{MA}^{1}(8 \mathrm{mg} / \mathrm{kg})^{4}$ & i.p. \\
\hline 4 & $\mathrm{I} / \mathrm{R}+\mathrm{CD}^{2}(10 \mathrm{mg} / \mathrm{kg})^{4}$ & i.p. \\
\hline 5 & $\mathrm{I} / \mathrm{R}+\mathrm{B}_{2}{ }^{3}(10 \mathrm{mg} / \mathrm{kg})^{4}$ & i.p. \\
\hline
\end{tabular}

1Selective monoacylglycerol lipase (MAGL) inhibitor (JZL184)

${ }^{2}$ Non selective cannabinoid receptor agonist, (Cannabidiol)

${ }^{3}$ Selektif $\mathrm{CB}_{2}$ receptor agonist (JWH133)

${ }^{4} \mathrm{All}$ treatments were made $30 \mathrm{~min}$ before mesenteric I/R.

Experimental protocol (Rat mesenteric ischemia / reperfusion model)

Rats were anesthetized with sodium thiopental (90mg/ $\mathrm{kg}$ ) by intraperitoneal injection. Midline abdominal incision was performed. Small bowel was externalized gently to the left onto a moist gauze and the SMA was isolated and ligated using a microvascular clamp. Animals were subjected to $30 \mathrm{~min}$ of ischemia by occlusion of the SMA. Intestinal ischemia was confirmed by observing loss of pulsation of the mesenteric artery and its branches as well as paleness of the jejunum and ileum. After ischemia period, the clamp was released and the bowel perfusion was controlled by the presence of pulse in mesenteric circulation Afterward the intestines were returned to the abdomen, the incision was sutured and covered with plastic wrap to minimize the loss of fluids.

At the end of $30 \mathrm{~min}$ of ischemia, the clamp was gently removed to allow reperfusion of the blood flow, which was confirmed by observing the pulsation of the artery and its branches on the intestine. At the end of the $24 \mathrm{~h}$ reperfusion period, intestinal and lung tissues and serum samples were collected for histopathologic and biochemical analyses. Terminal ileum strips at $10 \mathrm{~mm}$ length were immediately removed and transferred into a petri dish filled with physiological serum. Washing and removing the debris as well as the fat tissue around, the samples were carefully packed and stored at $80^{\circ} \mathrm{C}$. In the control group, the mesenteric artery was exposed but not occluded and the animals were followed for $30 \mathrm{~min}$ to simulate the ischemic interval. The reperfusion interval was also simulated and the animals were then subjected to the same procedures.

\section{Immunohistochemical Examinations}

ABC (Avidin-Biotin Complex) method was used to investigate caspase 3-8 and 9 activity from paraffin sections obtained after intestinal tissues were taken into $10 \%$ formaldehyde solution.
Transverse sections taken from the intestine samples at $4 \mu \mathrm{m}$ thickness are incubated at $62^{\circ} \mathrm{C}$ for deparaffinization and use of xylene and alcohol series. To prevent receptor masking caused by formaldehyde fixation in the tissue, sections were taken into citrate solution and high temperature was applied in the microwave. After exposing the antigenic determinant regions, the sections were taken from the citrate solution to water and kept at room temperature for 20 minutes.

After shaking the sections 3 times in phosphate buffered saline (PBS), 3\% hydrogen peroxide was applied for 15 minutes to prevent endogenous peroxidase activity and Ultra $\mathrm{V}$ block was used for 5 minutes to prevent non-specific binding. (Ultra V Block, LabVision, TA-015-UB). Following the blocking step, anti-caspase 3 (Thermo scientific, UK), anti-caspase 8 (Thermo scientific, UK) and anti-caspase 9 (Thermo scientific, UK) antibodies prepared in $1 / 100$ dilutions were administered for 1 hour in a humid environment. Sections taken back to PBS after secondary antibody application were treated with Streptavidin peroxidase complex for 10 minutes. DAB was applied as chromogen until 2 minutes of immune reaction to the sections taken into PBS and Mayers' hematoxylin was used for contrast staining. Sections were passed through alcohol series, treated with xylene, then closed with entellan and evaluated with Axio A1 Zeiss microscope.

H-Score: Results from immunohistochemistry were described in a histological score (H-SCORE) resulting from the number of cells with activated caspase-3, caspase-8 and caspase- 9 [0-100\% of cells] multiplied by the intensity of staining ( 1 = low, $2=$ medium and $3=$ high). For each section, the percentage of cells at each staining intensity level was calculated by using double blinded protocol [17]. The sections were observed under microscope at high magnification (200x). Mean score values were used for statistical analysis.

\section{Light microscopic procedures}

The rats in each group were sacrificed by deep anesthesia and lung and terminal ileum samples were collected from all animals. In each animal, tissue samples were fixed in $10 \%$ formalin solution for histopathologic examination. After fixation each tissue sample was routinely processed then embedded in paraffin. They were sectioned at $5 \mu \mathrm{m}$ thickness and stained with hematoxylin+eosin $[\mathrm{H}+\mathrm{E}]$. At least three randomly selected sections were scored to describe the lung and terminal ileum tissue damage $[18,19]$. The preparations obtained were visualized using an Axio Lab A1 microscope (Zeiss, Germany).

\section{Biochemical analysis}

\section{Total Antioxidant Capacity (TAC)}

TAC in serum was measured spectrophotometrically by using TAC colorimetric Assay Kit (Biovision, CA, USA) according to the manufacturer's instructions. It is based on the principle that $\mathrm{Cu}++$ ion is converted to $\mathrm{Cu}+$ by antioxidants. The reduced $\mathrm{Cu}+$ ion is chelated with a colorimetric probe giving a broad absorbance 
peak around $570 \mathrm{~nm}$, proportional to the TAC. The results are expressed as mM Trolox equivalent.

\section{TNF- $\alpha$, IL-6 and IL-1 $\beta$}

The serum levels of tumor necrosis factor-alpha (TNF- $\alpha$ ), interleukin 6 (IL-6) and interleukin 1beta (IL-1ß) (eBioscience, Vienna, Austria) of rats were determined using sandwich enzyme-linked immunosorbent assay technique according to the manufacturer's recommendations. The calibration range of the IL-6 assay was up to $2000 \mathrm{pg} / \mathrm{ml}$ and analytical sensitivity was $12 \mathrm{pg} / \mathrm{ml}$. The within-and total-run coefficient of variation (CV) values were $<5 \%$ and $<10 \%$, respectively. The calibration range of the IL- $1 \beta$ assay was up to $2000 \mathrm{pg} / \mathrm{ml}$ and analytical sensitivity was $4 \mathrm{pg} / \mathrm{ml}$. The within and total run $\mathrm{CV}$ values were $<10 \%$ and $<10 \%$, respectively. The calibration range of the TNF- $\alpha$ assay was up to $2500 \mathrm{pg} / \mathrm{ml}$ and analytical sensitivity was $11 \mathrm{pg} / \mathrm{ml}$. The within and total run $\mathrm{CV}$ values were $<5 \%$ and $<10 \%$, respectively.

\section{MDA and Caspase-3 activity}

Tissues were homogenized according to the manufacturer's recommendations by using a glass teflon homogenizer (Ultra Turrax IKA T18 Basic). The homogenate was then centrifuged at $1000 \mathrm{~g}$ for 10 minutes and the supernatant fluid was taken and used for malondialdehyde levels (MDA) and Caspase- 3 activity measurement. Protein concentrations were measured with Lowry method [20].

MDA was measured in the supernatant using a commercial kit (Biovision, CA, USA) that is based on the colorimetric method. MDA reacts with Thiobarbituric acid (TBA) to form the MDA-TBA adduct with a maximum absorption at $532 \mathrm{~nm}$, that was measured using microtiter plate reader (Poweam Medical, Nanjing, China). The MDA levels in the tissue were calculated from the Standard curve and expressed as nanomoles per milligram protein.

Caspase-3 activiy was analyzed using colorimetric assay kit (Biovision, CA, USA). The assay is based on spectrophotometric detection of the chromophore p-nitroaniline after cleavage from the labeled substrate DEVD-pNA. p NA light emission can be quantified using microtiter plate reader (Poweam Medical, Nanjing, China) at $405 \mathrm{~nm}$. Caspase- 3 activity results are expressed as nanomoles per milligram of tissue protein.

\section{Tissue protein assay}

Protein concentration in the supernatant fraction was determined utilizing the method of Lowry et al. [20]. [Reagent A: $2 \% \mathrm{Na} 2 \mathrm{CO} 3$ in $0.1 \mathrm{~N} \mathrm{NaOH}$. Reagent B: $0.5 \% \mathrm{CuSO} 4.5 \mathrm{H} 20$ in $1 \%$ sodium or potassium tartrate. Reagent C: alkaline copper solution. $50 \mathrm{ml}$ of Reagent A was mixed with $1 \mathrm{ml}$ of Reagent B. Reagent E Folin reagent. (The Folin Ciocalteau reagent was obtained from Sigma Co.). $0.2 \mathrm{ml}$ of the sample and $1 \mathrm{ml}$ of Reagent $\mathrm{C}$ were mixed and were left undisturbed for $10 \mathrm{~min}$ at room temperature. Then $0.10 \mathrm{ml}$ reagent $\mathrm{E}$ was added and the mixture was left for an additional 30min. Absorbance was measured at $750 \mathrm{~nm}$ with a Shimadzu UV 1601 spectrophotometer. Bovine serum albumin (BSA) from Sigma Co. was used as the protein standard. The protein concentration of the supernatant was calculated.

\section{Chemicals}

The following chemicals were used in this study: Cannabidiol and JWH133 EIA kit were purchased from Cayman Chemical (Michigan, U.S.A.). JZL184 was purchased from Santacruz Biotechnology (Dallas, Texas, U.S.A.). Rat IL-1, IL-6, TNF- $\alpha$ ELISA kits were purchased from eBioscience (West Coast, U.S.A.). Caspase 3 and 9 antibodies were purchased from Lab Vision (CA, U.S.A.). Caspase 8 antibody was purchased from Abcam (Cambridge, MA, U.S.A.). Caspase-3, lipid peroxidation (malondialdehyde, MDA) and total antioxidant capacity (TAC) colorimetric assay kits were purchased from BioVision (California, U.S.A.).

\section{Statistical analysis of results}

Statistical analyses were performed with SPSS 18.0 software (SPSS Inc., Chicago, IL, USA). Results were expressed as mean \pm SEM. The Mann-Whitney $U$ test is used to compare two groups in terms of numerical variables, and the Kruskal-Wallis variance analysis will be used to compare three or more groups. In KruskalWallis analysis of variance, a two-tailed comparison of subgroups was performed using the Bonferroni corrected Mann-Whitney $\mathrm{U}$ test. $\mathrm{P}$ value of less than 0.05 was considered statistically significant for all tests.

\section{Results}

\section{The effects of mesenteric I / R on ileum and lung tissues}

On hematoxylin-eosin staining examination, a statistically significant tissue damage was determined for alveolar congestion, bleeding, neutrophilic infiltration and alveolar wall thickness on lung tissue and mucosal damage on intestinal tissue (Figure 1). Caspase 3, 8 and 9 expressions of intestinal and lung tissues of I/R group were found to be statistically higher compared to the control group on immunohistochemical examination respectively (Figure 2 and Figure 3).

\section{Effects of MAGL inhibitor JZL184 on ileum and lung tissues injury induced by mesenteric I/R}

On hematoxylin-eosin staining of intestinal tissue, JZL184 reduced intestinal mucosal damage compared to the ischemia group, but it was not statistically significant (Figure 1). JZL184 significantly reduced alveolar congestion, hemorrhage, neutrophilic infiltration and alveolar wall thickness in the lung tissue (Figure1). JZL184 significantly reduced caspase 3, 8 and 9 expressions in intestinal tissue (Figure 2) and caspase 8 expression in lung tissue on immunohistochemical examination (Figure 3). 

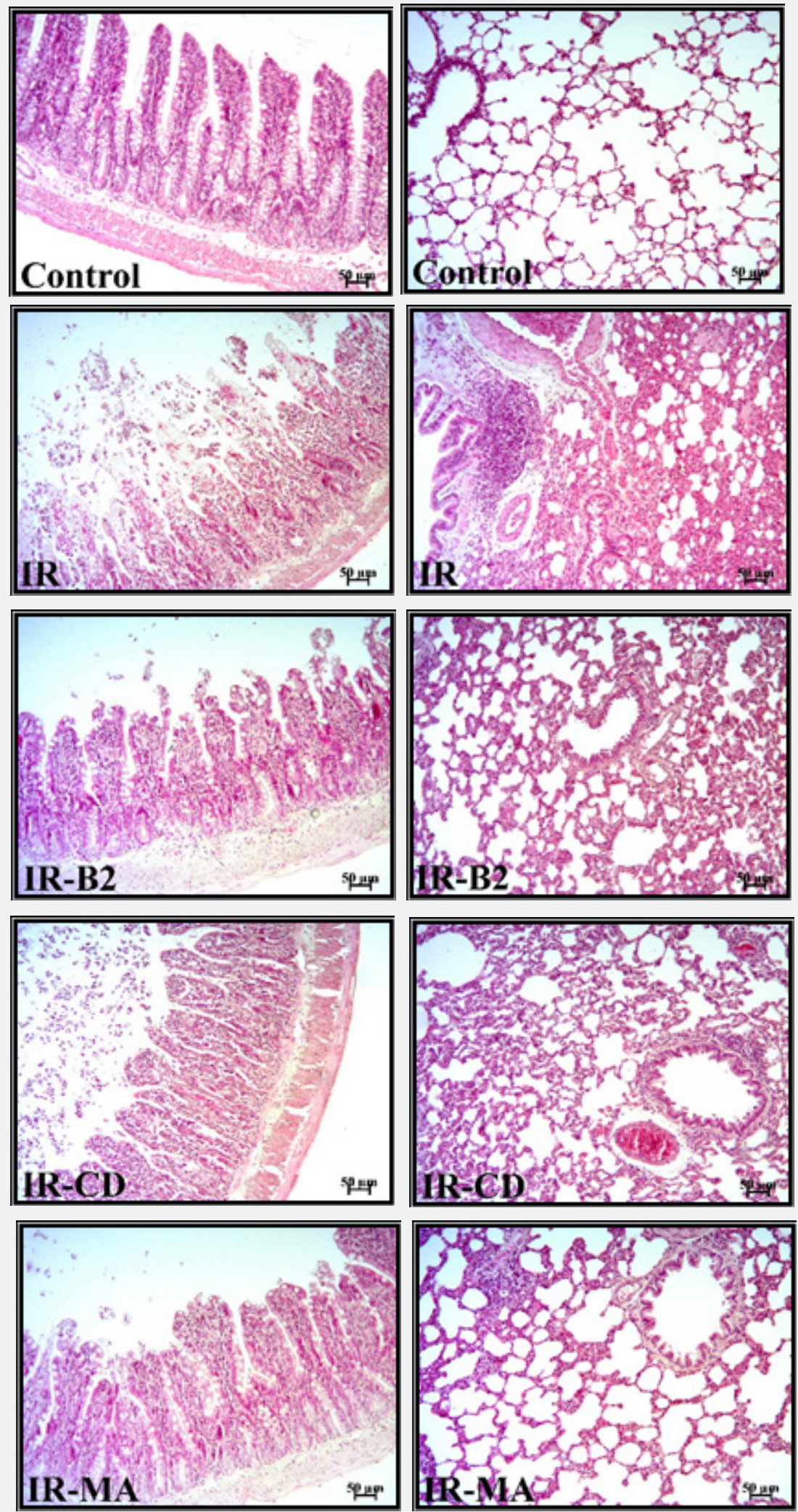

Figure 1: Rat Lung Tissue, immunohistochemistry staining results. A (control), B (IR), C (IR+ B2), D (IR+CD), E (IR+MA). Small intestine (left panel) and lung tissues (right panel) after intestinal ischemia/reperfusion (IR) were stained with hematoxylin-eosin and examined under light microscopy at scale bar $50 \mu \mathrm{m}$. Representative images for control, IR, IR-B2, IR-CD and IR-MA groups. 

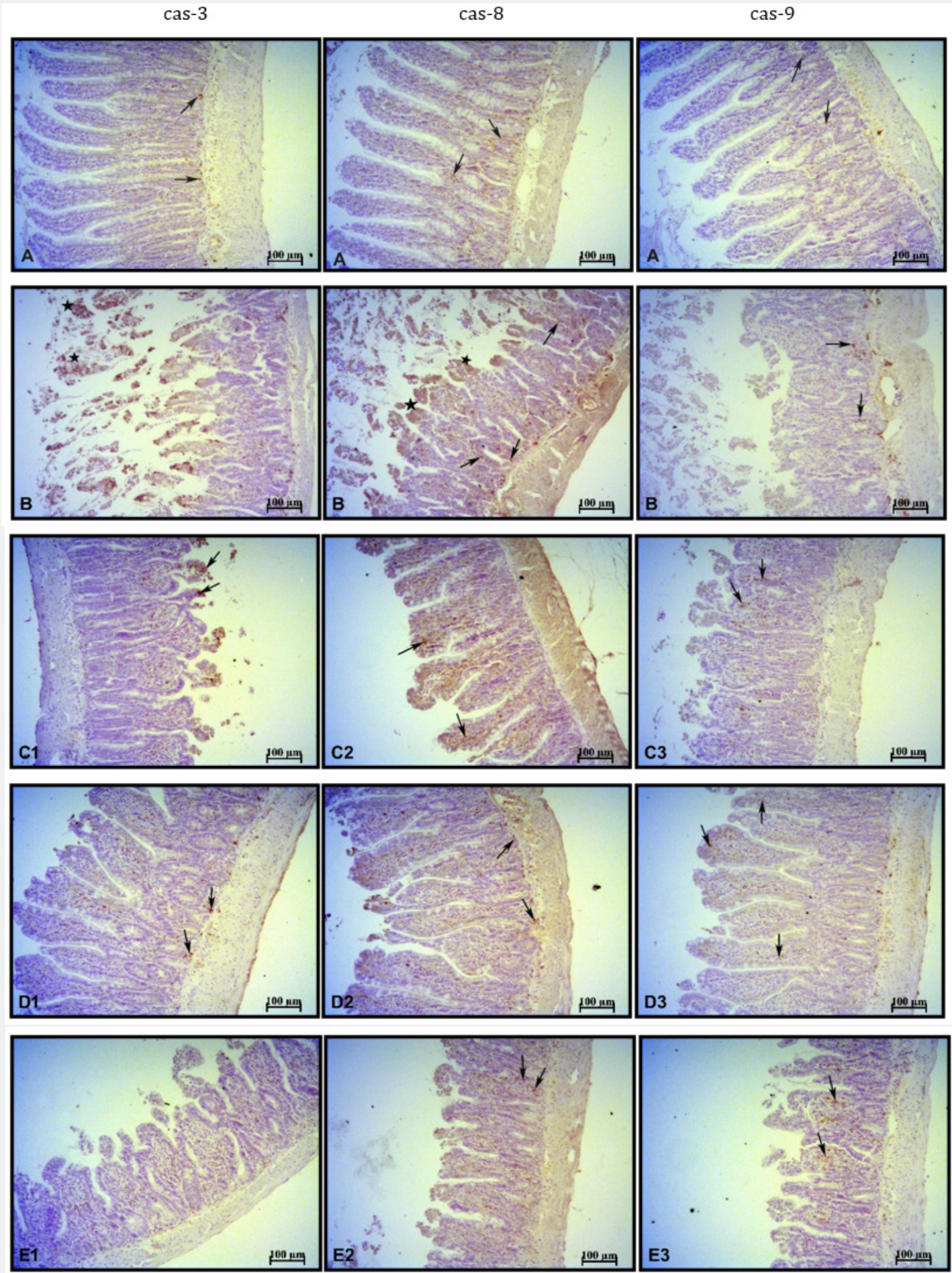

Figure 2: Rat Intestinal Tissue, immunohistochemistry staining results. A (control), $B(I R), C$ (IR+ B2), D (IR+CD), E (IR+MA).

$A$ (control), B (IR), C (IR+ B2), D (IR+CD), E (IR+MA). When caspase 3-8 and 9 expressions are evaluated in the control group, an immune positive reaction is observed in intestinal villi and crypts close to the muscularis mucosa (black arrows). Similarly, weak staining is observed in the submucosa layer. Contrary to the control group, strong staining was observed in the IR group, especially in the epithelial cells of the surface villus, in the lamina propria in the near-surface areas (black arrow), and in the cells spilled into the lumen (star) due to ischemiareperfusion damage. A significant decrease in caspase 3-8 and 9 expression was observed in the treated groups. Weak staining similar to the control group is observed in intestinal villi, crypts (black arrows) and submucosa, especially in IR+CD and IR+MA groups. (Scale bar $=100 \mu \mathrm{m})$ 

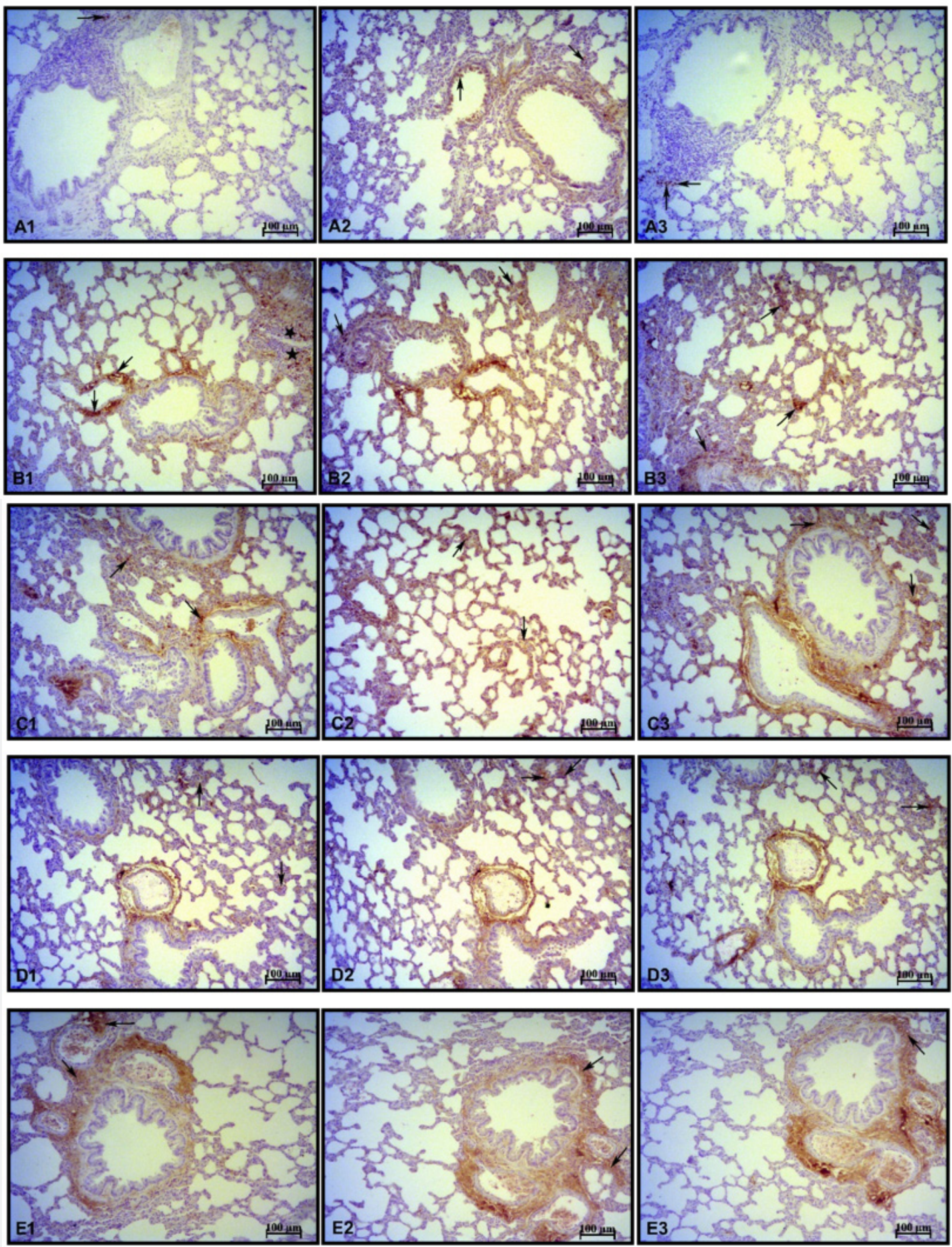

Figure 3: Small intestine (left panel) and lung tissues (right panel) harvested 3 hours after intestinal ischemia/reperfusion (IR) were stained with hematoxylin-eosin and examined under light microscopy at scale bar 50 $\mathrm{mm}$. Representative images for control, IR, IR-B2, IR-CD and IR-MA groups.

A (control), B (IR), C (IR+ B2), D (IR+CD), E (IR+MA). When the expression of caspase 3-8 and 9 in rat lung tissue is examined, strong staining is observed in the bronchiole and alveolar wall (black arrows), especially in the group in which ischemia-reperfusion injury was created (IR). In addition, a strong immune reaction is observed in areas with cell infiltration due to damage, unlike the control group. Especially in the (IR+MA) group, a staining similar to the control group draws attention, except for the bronchiole wall. (Scale bar $=100 \mu m)$. 
Effects of non-selective cannabinoid receptor agonist, cannabidiol (CBD) on ileum and lung tissues injury induced by mesenteric $I / R$

On hematoxylin-eosin staining of intestinal tissue, CBD decreased intestinal mucosal damage compared to the ischemia group, but it was not statistically significant (Figure 1). CBD significantly reduced caspase 3, 8 and 9 expressions in both intestinal and lung tissues on immunohistochemical examination respectively (Figure 2 and Figure 3).

\section{Influence of selective CB2 receptor agonist JWH133 on ileum and lung tissues injury induced by mesenteric I/R}

JWH133 did not decrease intestinal mucosal damage compared to ischemia group on hematoxylin-eosin staining (Figure 1). JWH133 significantly reduced neutrophilic infiltration and alveolar wall thickness in lung tissue. It has decreased alveolar congestion and hemorrhage considerably compared to ischemia group, but this decrease was not found statistically significant.

Although JWH133 reduced the values of caspase 3 and 8 expression in the intestinal tissue considerably compared to the pathology group on immunohistochemical examination, this decrease was not found statistically significant (Figure 2). There was no difference in caspase 9 expression between I/R group and JWH133 treatment group also. JWH133 did not cause any change in caspase 3, 8 and 9 expressions in lung tissue compared to the ischemia group (Figure 3).

\section{Effects of cannabinoids on biochemical parameters (TAC, MDA, TNF- $\alpha$, IL-6, IL-1 $\beta$ and Caspase-3 activity)}

Ileum caspase- 3 activity and MDA levels of I/R group were found to be higher compared to the control group but this increase were not found statistically significant. Additinally, serum TNF- $\alpha$, IL-6, IL-1 $\beta$, TAC levels of I/R group were also found to be higher compared to the control group but this increase also were not found statistically significant.

\section{Discussion}

The present study showed that, pre-ischemia treatment with drugs that affect the cannabinoid system effectively protected against lung damage mediated by $\mathrm{I} / \mathrm{R}$ in rats. The highest protection against intestinal and lung tissue damage was seen in the cannabidiol treatment group. While the MAGL inhibitor JLZ184 showed similar protection against intestinal tissue damage as cannabidiol, this effect was lower in the lung. Among the drugs used related to the cannabinoid system, the least effect was observed in the selective cannabinoid 2 receptor agonist JWH133 treatment group. On the other hand, although an increase was observed in the ischemia-reperfusion group compared to the control group, no significant differences were found in our current experimental conditions in the tissue and serum biochemical parameters.
Intestinal ischemia plays a fundamental role in the pathophysiology of various diseases, and subsequent reperfusion results in more severe tissue damage than ischemia alone [21]. Therefore, ischemia followed by reperfusion is a major mechanism of tissue injury in various pathologies i.e., cardiovascular and pulmonary diseases, organ transplantation, stroke and limb injury. The events that occur during I/R are complex and, although well studied, their pathophysiology and treatment have not been fully clarified and new researchs are needed [22]. Intestinal ischemia develops in two different conditions. It may develop as a result of arterial occlusion by thrombus or embolus, or as a result of nonocclusive processes such as low mesenteric flow conditions such as sepsis and heart failure.

Occlusion is most common in the celiac artery, superior mesenteric artery and inferior mesenteric artery [23]. When arterial ischemia occurs, it causes tissue hypoperfusion and oxygen deficiency disrupts cellular homeostasis and initiates tissue damage. The obstruction of arterial blood flow causes hypoxia and leads to dysfunction of the electron transport chain in mitochondria. If ischemia continues, this damage causes cellular changes that result in necrosis. Depending on the duration of the ischemic process, tissue damage may be exacerbated when oxygen is reintroduced to the tissues (oxygen paradox). After reperfusion, restoring blood flow to ischemic tissue increases the formation of ROS due to the lower concentration of antioxidants in ischemic cells. ROS causes oxidative stress, which stimulates endothelial dysfunction, DNA damage and local inflammatory responses. $\mathrm{I} / \mathrm{R}$ is characterized by intense inflammation predominantly in the mucosa and submucosa leading to endothelial destruction. Inflammatory cascades and oxidative stress can then cause a cytokine storm, causing cell death caused by damage to cellular structures. I/R can trigger different mechanisms in tissue, leading to microvascular damage, cellular necrosis, or apoptosis [23,24].

While I/R that develops in mesenteric blood vessels often causes acute vascular insufficiency and local tissue damage, it can also cause multi-organ failure with high morbidity and mortality rates $[4,5,24,25]$. It has been shown that the lungs are particularly susceptible to distant organ damage due to intestinal I/R and I/R causes lung tissue damage [6]. After I/R development, pulmonary injury may rapidly progress to respiratory failure and ARDS. ARDS, which emerges as an important component of multi-organ dysfunction syndrome, is defined as "inflammation syndrome and increased capillary endothelial permeability". Inflammation mediators play a key role in the pathogenesis of ARDS.

However, the mechanisms causing inflammation in the intestines and distant organs have not been fully clarified $[2,3,5$, 25-27]. We demonstrated for the first time the roles of oxidized low-density lipoprotein (oxLDL) and peripheral benzodiazepine receptors in lung tissue damage after intestinal I/R [1,2,28]. We also shown that strong inducible nitric oxide synthase (iNOS) staining reactions in both the proximal tubulus epithelial cell 
cytoplasm and glomerular basement membrane of kidney tissues after mesenteric I/R [2].

In recent years, it has been determined that the endocannabinoid system may play a role in the pathogenesis of many diseases, and the idea that drugs related to this system may be a new therapeutic target has been coming to the fore [10]. The discovery of the CB1 and CB2 cannabinoid receptors and their major ligands $\mathrm{N}$-arachidonoylethanolamide (anandamide) and 2-arachidonoylglycerol (2-AG) and enzymes led to the characterization of the endocannabinoid system [29,30]. This system has become a subject of great interest in pharmacology due to its remarkable distribution in mammals and its capacity to play a modulating role in diverse physiological functions including immunomodulation and inflammation. 2-AG and anandamide are regulated by the catabolic enzymes MAGL and fatty acid amide hydrolase (FAAH), respectively [31].

Endocannabinoids regulate immune cell functions via cannabinoid receptors or numerous metabolites [32]. Increasing evidence suggests that the endocannabinoid system is present in human lungs and that most cell types express cannabinoid receptors. A study of the distribution of cannabinoid receptors among human organs found both CB1 and CB2 mRNA in the lungs and the bronchial tissue [33]. In addition, many structural and immune cells are able to synthesize endocannabinoids in response to inflammatory stimuli [34]. The effect of this on lung functions and diseases is not fully understood.

In our study, MAGL inhibitor JZL184 and cannabidiol showed a protective effect against intestinal and lung tissue damages induced by mesenteric I/R. Both drugs had been a reducing effect on caspases involved in I/R mediated apoptosis mechanisms in intestinal and lung tissues. On the other hand, JWH133 only showed an effect on increased caspase expression in intestinal tissue (not statistically significant), not lung tissue. These results show that the increase of endocannabinoids and non-selective cannabinoid receptor agonists provide more effective protection in mesenteric I/R mediated lung injury, and the effect of selective B2 receptor agonist remains low. If all groups are compared, the highest protection against intestinal and lung tissue damage was seen in the cannabidiol treatment group. Treatment with JZL184 has been reported to block cytokine expression in the gut or blood in a gastric inflammation model [9]. JZL184 given before LPSinduced ALI has been found to have an anti-inflammatory effect [31].

Xiong et. al. showed that pretreatment with MAGL inhibitor, URB602, significantly reduced IR-induced lung injury and inflammation. URB602 inhibited lung ischemia-reperfusion injury and inflammation by increasing 2-AG level and reducing downstream metabolites from arachidonic acid to prostaglandin $\mathrm{I}_{2}\left[\mathrm{PGI}_{2}\right]$, thromboxane $\mathrm{B}_{2}\left[\mathrm{TXB}_{2}\right]$ and leukotrienes $\mathrm{B}_{4}\left[\mathrm{LTB}_{4}\right]$ and inflammatory markers interleukin 6 [IL-6] and tumor necrosis factor- $\alpha[$ TNF- $\alpha]]$ in lung tissues [35]. These results support the effects of JLZ184 in our study. Recent studies also support an important role of endocannabinoids against I/R induced tissue damage, including cerebral, myocardial, renal, liver tissues [3638].

Cannabidiol is the major non-psychoactive cannabinoid component derived from the plant Cannabis sativa. It possesses powerful antioxidant and anti-inflammatory activities. Previous reports proved that cannabidiol may have therapeutic utility in a number of conditions involving inflammation and oxidative stress, as diabetes mellitus, rheumatoid arthritis and neurodegenerative disorders and the protective effect of cannabidiol was also demonstrated in animal models with cerebral, myocardial and liver ischemia/reperfusion [36]. It was reported that a single dose of cannabidiol is able to induce a decrease in several lung inflammation parameters, such as leukocyte migration [neutrophil, macrophages, and lymphocytes], myeloperoxidase activity, pro-inflammatory cytokine/chemokine production, and vascular permeability during the course of a murine model of LPSinduced acute lung injury [34]. However, the exact mechanisms of action of cannabidiol remain obscure.

The exact molecular mechanisms by which cannabinoids modulate apoptosis signaling have not been fully elucidated, nevertheless, the current evidence supports their importance as promising therapeutic targets to regulate cell damage signaling mechanisms. Apoptosis is a physiological cell death mechanism that occurs when programs in the genetic codes of multicellular organisms are activated as a result of various stimuli [39]. Regardless of whether the activation of apoptosis mechanisms starts via intrinsic or extrinsic pathways, when caspases 8 and 9 are activated, the death mechanism starts irreversibly. After activation of caspase 8 or 9 , activation of caspase- 3 and caspase- 6 , known as executioner caspases, takes place. Terminator caspases affect a large number of cell components and thus enable apoptosis to occur [40-45].

Mukhopadhyay et al. found that cannabidiol had a protective effect on liver inflammation, oxidative/nitrative tissue damage and cell death, and had a significant reduction effect on apoptotic bodies in apoptotic cells, which increased approximately 10 times in the hepatic I/R model [46]. In our study, supporting the literature, it was observed that cannabidiol decreased intestinal and lung tissue caspase 3, 8 and 9 expressions. These findings show that cannabidiol has an effect on apoptosis pathways that develop in mesenteric I/R damage via CB1 and CB2 receptors.

McKallip et al. found that CB2 receptor indirectly provides a reduction in apoptotic induction in leukemia cells. They showed that cannabidiol reduced the activation of caspase 3,8 and 9, the cleavage of poly (ADP-ribose) and the level of Bid (proapoptotic protein) and had an effect on intrinsic and extrinsic apoptotic pathways [47]. Jiang et al. shown that JZL184 caused a decrease 
in neutrophil and macrophage infiltration and proinflammatory cytokine expression in a rat muscle contusion model, thus creating an anti-inflammatory effect. It has been reported that JZL184 exerts this effect through cannabinoid CB1 and CB2 receptors and has a positive effect on muscle recovery [48].

With enzymatic hydrolysis of 2-AG by MAGL, the endocannabinoid signal is interrupted, and the effect disappears. JZL184 is a selective inhibitor of the MAGL enzyme. In this way, JZL184 increases the level of 2-AG acting on $\mathrm{CB}_{1}$ and $\mathrm{CB}_{2}$ receptors by preventing hydrolysis. Costala-de-Souza et al. showed that inhibition of MAGL with a single dose of JZL184 $(16 \mathrm{mg} / \mathrm{kg}$, ip) reduced leukocytes migration to the lungs, vascular permeability, cytokine and chemokine levels in bronchoalveolar lavage fluid, and adhesion molecule expression in blood and BAL in a model of LPS-induced acute lung injury in mice. Whether JZL184 exerts an anti-inflammatory effect by inhibiting the MAGL enzyme was investigated using the CB1 receptor selective antagonist AM281 and the $\mathrm{CB}_{2}$ receptor selective antagonist AM630. AM281 and AM630 abolished the effects of the anti-inflammatory effects induced by JZL184. They stated that in acute lung injury developing following LPS administration, JZL184 inhibits the MAGL enzyme and increases the level of 2-AG and creates an anti-inflammatory effect through CB1, CB2 receptors [49].

In our study, consistent with the literature, MAGL inhibitor JZL184 was administered intraperitoneally at a dose of $8 \mathrm{mg} / \mathrm{kg}$ in lung injury due to mesenteric I/R injury; significantly decreased alveolar congestion, hemorrhage, neutrophilic infiltration and alveolar wall thickness in lung tissue. Although it reduced intestinal mucosal damage in intestinal tissue, this result was not statistically significant. As shown by different experimental models in the literature [32, 37, 50-53], in accordance with our results, JZL184 has been shown to have healing effects on lung injury. In the Costala-de-Souza's study, JZL184 was administered intraperitoneally at a dose of $16 \mathrm{mg} / \mathrm{kg}$. In our study, JZL184 was administered in the same way at a dose of $8 \mathrm{mg} / \mathrm{kg}$ and similar results were encountered. These findings suggest that JZL184 has positive effects on lung injury even at lower doses.

At the same time, in our study, it was observed that JZL184 decreased caspase 3, 8, and 9 levels in intestinal tissue and caspase 8 levels in lung tissue at a statistically significant level. These findings show that JZL184 plays a role in intrinsic and extrinsic apoptotic mechanisms by increasing the tonus of 2-AG, which is one of the most known endocannabinoids as a result of inhibiting the MAGL enzyme. Liu et al. found that JWH133 significantly alleviated paraquat-induced pulmonary edema and histopathological changes in the lung tissue. The effects of the $\mathrm{CB}_{2}$ receptor on the regulation of paraquat-induced proinflammatory activity in rats were investigated in this study. It has been stated that it reduces TNF- $\alpha$ and IL-1 secretion, lung tissue MPO levels, increase in $\mathrm{PaO}_{2}$ in arterial blood, and inhibits MAPK and NF-kB activation. It has been reported that suppression of the activation of MAPK and NF-kB pathways may potentially contribute to the protective effect of JWH133 against paraquat-induced acute lung injury [54].

Similarly, Li Q et al. found that, JWH133 significantly reduced the infarct area, decreased caspase 3 and 9 activity, cytochrome $\mathrm{C}$ outflow, and increased phosphorylated Akt in myocardial I/R model. All these findings were observed to be reversed by the PI3K inhibitor wortmannin and the $\mathrm{CB}_{2}$ receptor antagonist AM630. With these results, they stated that activation of $\mathrm{CB}_{2}$ receptors with JWH133 inhibited ischemia-reperfusion-induced apoptosis via the PI3K/Akt signaling pathway [55]. In our study, it was observed that JWH133 reduced caspase 3 and 8 levels in intestinal tissue, but this decrease was not statistically significant and had no effect on caspases in lung tissue at the dose used.

Considering all the results, it was concluded that cannabinoid receptors, which have been shown to be present in the lung and intestine, may play a role in the pathophysiological mechanisms of mesenteric I/R-mediated intestinal and lung tissue damage. Non-selective cannabinoid receptor agonist cannabidiol at a dose of $10 \mathrm{mg} / \mathrm{kg}$, MAGL enzyme inhibitor JZL184 at a dose of $8 \mathrm{mg} / \mathrm{kg}$ and selective $\mathrm{CB}_{2}$ receptor agonist JWH133 at a dose of $10 \mathrm{mg} / \mathrm{kg}$ may have protective potential against this damage.

\section{Acknowledgements}

We thank Hasan Tahsin Yilmaz and Bayram Cakan for their assistance in research laboratory.

\section{References}

1. Tekin IO, Sipahi EY, Comert M, Acikgoz S, Yurdakan G (2009) Lowdensity lipoproteins oxidized after intestinal ischemia/reperfusion in rats. Journal of Surgical Research 157(1): e47-54.

2. Yurdakan G, Tekin I0, Comert M, Acikgoz S, Sipahi EY (2012) The presence of oxidized low-density lipoprotein and inducible nitric oxide synthase expression in renal damage after intestinal ischemia reperfusion. Kaohsiung J Med Sci 28(1): 16-22.

3. Tsushima K, King LS, Aggarwal NR, De Gorordo A, D Alessio FR, et al. (2009) Acute lung injury review. Intern Med 48(9): 621-630.

4. Wu MY, Yiang GT, Liao WT, Tsai AP, Cheng YL, et al. (2018) Current Mechanistic Concepts in Ischemia and Reperfusion Injury. Cell Physiol Biochem 46(4): 1650-1667.

5. Stringa P, Lausada N, Romanin D, Portiansky E, Zanuzzi C, et al. (2016) Pretreatment Combination Reduces Remote Organ Damage Secondary to Intestinal Reperfusion Injury in Mice: Follow-up Study. Transplant Proc 48(1): 210-216.

6. Fan E, Brodie D, Slutsky AS (2018) Acute Respiratory Distress Syndrome: Advances in Diagnosis and Treatment. JAMA 319(7): 698710 .

7. Di Marzo V (2018) New approaches and challenges to targeting the endocannabinoid system. Nat Rev Drug Discov 17(9): 623-639.

8. Fu Q, Zheng Y, Dong X, Wang L, Jiang CG (2017) Activation of cannabinoid receptor type 2 by JWH133 alleviates bleomycin-induced pulmonary fibrosis in mice. Oncotarget 8(61): 103486-103498.

9. Fouad AA, Jresat I (2011) Therapeutic potential of cannabidiol against ischemia/reperfusion liver injury in rats. Eur J Pharmacol 670(1): 216223. 
10. Fraguas-Sanchez AI, Torres-Suarez AI (2018) Medical Use of Cannabinoids. Drugs 78(16): 1665-1703.

11. White CM (2019) A Review of Human Studies Assessing Cannabidiol's (CBD) Therapeutic Actions and Potential. J Clin Pharmacol 59(7): 923934.

12. Bruni N, Della Pepa C, Oliaro-Bosso S, Pessione E, Gastaldi D et al. (2018) Cannabinoid Delivery Systems for Pain and Inflammation Treatment. Molecules 23(10): 2478.

13. Alves P, Amaral C, Teixeira N, Correia DSG (2020) Cannabis sativa: Much more beyond $\Delta$ 9-tetrahydrocannabinol. Pharmacol Res 157: 104822.

14. Kreitzer FR, Stella N (2009) The therapeutic potential of novel cannabinoid receptors. Pharmacol Ther 122(2): 83-96.

15. Di Marzo V, Piscitelli F (2011) Gut feelings about the endocannabinoid system. Neurogastroenterol Motil 23(5): 391-398.

16. De Filippis D, Esposito G, Cirillo C, Cipriano M, De Winter BY et al. (2011) Cannabidiol reduces intestinal inflammation through the control of neuroimmune axis. PLoS One 6(12): e28159.

17. Sapmaz MM, Topcu TY, Uz YH, Inan M, Omurlu IK, et al. (2013) Vitamin E modulates apoptosis and c-jun N-terminal kinase activation in ovarian torsion-detorsion injury. Exp Mol Pathol 95(2): 213-219.

18. Li Y, Yao JH, Hu XW, Fan Z, Huang L, et al. (2011) Inhibition of Rho kinase by fasudil hydrochloride attenuates lung injury induced by intestinal ischemia and reperfusion. Life Sci 88(1-2): 104-109.

19. Hierholzer C, Kalff JC, Audolfsson G, Billiar TR, Tweardy DJ, et al. (1999) Molecular and functional contractile sequelae of rat intestinal ischemia/reperfusion injury. Transplantation 68(9): 1244-1254.

20. Lowry OH, Rosebrough NJ, Farr AL, Randall RJ (1951) Protein measurement with the Folin phenol reagent. J Biol Chem 193(1): 265275.

21. Cerqueira NF, Hussni CA, Yoshida WB (2005) Pathophysiology of mesenteric ischemia/reperfusion: a review. Acta Cir Bras 20(4): 336343 .

22. Wu MY, Yiang GT, Liao WT, Tsai AP, Cheng YL, et al. (2018) Current Mechanistic Concepts in Ischemia and Reperfusion Injury. Cell Physiol Biochem 46(4): 1650-1667.

23. Gonzalez LM, Moeser AJ, Blikslager AT (2015) Animal models of ischemia-reperfusion-induced intestinal injury: progress and promise for translational research. Am J Physiol Gastrointest Liver Physiol 308(2): G63-75.

24. Ito H, Sadatomo A, Inoue Y, Yamada N, Aizawa E, et al. (2019) Role of TLR5 in inflammation and tissue damage after intestinal ischemiareperfusion injury. Biochem Biophys Res Commun 519(1): 15-22.

25. Fernandes de MDS, Barbeiro DF, Koike MK, Barbeiro HV, Pinheiro da SF, et al. (2018) Diazoxide reduces local and remote organ damage in a rat model of intestinal ischemia reperfusion. J Surg Res 225: 118-124.

26. Yilmaz SE (2015) Causes of failure in acute respiratory distress syndrome modeling and treatment in animal research and new approaches. World Journal of Respirology 5(2): 65-68.

27. Yilmaz SE (2014) Experimental models of acute respiratory distress syndrome. J Transl Intern Med 2(4): 154-159.

28. Kaynar G, Yurdakan G, Comert F, Yilmaz SE (2013) Effects of peripheral benzodiazepine receptor ligand Ro5-4864 in four animal models of acute lung injury. J Surg Res 182(2): 277-284.

29. Turcotte C, Chouinard F, Lefebvre JS, Flamand N (2015) Regulation of inflammation by cannabinoids, the endocannabinoids 2-arachidonoylglycerol and arachidonoyl-ethanolamide, and their metabolites. J Leukoc Biol 97(6): 1049-1070.
30. Matsuda LA, Lolait SJ, Brownstein MJ, Young AC, Bonner TI (1990) Structure of a cannabinoid receptor and functional expression of the cloned cDNA. Nature 346(6284): 561-564.

31. Costola de SC, Ribeiro A, Ferraz de PV, Calefi AS, Aloia TP, et al. (2013) Monoacylglycerol lipase (MAGL) inhibition attenuates acute lung injury in mice. PLoS One 8(10): e77706.

32. Galiegue S, Mary S, Marchand J, Dussossoy D, Carriere D, (1995) Expression of central and peripheral cannabinoid receptors in human immune tissues and leukocyte subpopulations. Eur J Biochem 232(1): 54-61.

33. Turcotte C, Blanchet MR, Laviolette M, Flamand N (2016) Impact of Cannabis, Cannabinoids, and Endocannabinoids in the Lungs. Front Pharmacol 7: 317.

34. Ribeiro A, Ferraz de Paula V, Pinheiro ML, Vitoretti LB, Mariano SDP, et al. (2012) Cannabidiol, a non-psychotropic plant-derived cannabinoid, decreases inflammation in a murine model of acute lung injury: role for the adenosine $\mathrm{A}(2 \mathrm{~A})$ receptor. Eur J Pharmacol 678(1-3): 78-85.

35. Alhouayek M, Lambert DM, Delzenne NM, Cani PD, Muccioli GG (2011) Increasing endogenous 2-arachidonoylglycerol levels counteracts colitis and related systemic inflammation. FASEB J 25(8): 2711-2721.

36.Xiong Y, Yao H, Cheng Y, Gong D, Liao X, et al. (2018) Effects of monoacylglycerol lipase inhibitor URB602 on lung ischemiareperfusion injury in mice. Biochem Biophys Res Commun 506(3): 578-584.

37. Fouad AA, Al Mulhim AS, Jresat I (2012) Cannabidiol treatment ameliorates ischemia/reperfusion renal injury in rats. Life Sci 91(7-8): 284-292.

38. Booz GW (2011) Cannabidiol as an emergent therapeutic strategy for lessening the impact of inflammation on oxidative stress. Free Radic Biol Med 51(5): 1054-1061.

39. Favaloro B, Allocati N, Graziano V, Di Ilio C, De Laurenzi V (2012) Role of apoptosis in disease. Aging (Albany NY) 4(5): 330-349.

40. Sartorius U, Schmitz I, Krammer PH (2001) Molecular mechanisms of death-receptor-mediated apoptosis. Chembiochem 2(1): 20-29.

41. Wu H, Che X, Zheng Q, Wu A, Pan K, et al. (2014) Caspases: a molecular switch node in the crosstalk between autophagy and apoptosis. Int J Biol Sci 10(9): 1072-1083.

42. McLuskey K, Mottram JC (2015) Comparative structural analysis of the caspase family with other clan CD cysteine peptidases. Biochem 466(2): 219-232.

43. Ghatage DD, Gosavi SR, Ganvir SM, Hazarey VK (2012) Apoptosis: Molecular mechanism. India Journal of Orofacial Sciences 4(2): 103107.

44. Elmore S (2007) Apoptosis: a review of programmed cell death. Toxicol Pathol 35(4): 495-516.

45. Nagata S (2018) Apoptosis and Clearance of Apoptotic Cells. Annu Rev Immunol 36: 489-517.

46. Mukhopadhyay P, Rajesh M, Horvath B, Batkai S, Park O, et al. (2011) Cannabidiol protects against hepatic ischemia/reperfusion injury by attenuating inflammatory signaling and response, oxidative/nitrative stress, and cell death. Free Radic Biol Med 50(10): 1368-1381.

47. McKallip RJ, Jia W, Schlomer J, Warren JW, Nagarkatti PS, et al. (2006) Cannabidiol-induced apoptosis in human leukemia cells: A novel role of cannabidiol in the regulation of p22phox and Nox4 expression. Mol Pharmacol 70(3): 897-908.

48. Jiang SK, Zhang M, Tian ZL, Wang M, Zhao R, et al. (2015) The monoacylglycerol lipase inhibitor JZL184 decreases inflammatory response in skeletal muscle contusion in rats. Eur J Pharmacol 761: 1-10. 
49. Kerr DM, Harhen B, Okine BN, Egan LJ, Finn DP, et al. (2013) The monoacylglycerol lipase inhibitor JZL184 attenuates LPS-induced increases in cytokine expression in the rat frontal cortex and plasma: differential mechanisms of action. Br J Pharmacol 169(4): 808-819.

50. Ghosh S, Wise LE, Chen Y, Gujjar R, Mahadevan A, et al. (2013) The monoacylglycerol lipase inhibitor JZL184 suppresses inflammatory pain in the mouse carrageenan model. Life Sci 92(8-9): 498-505.

51. Ma M, Bai J, Ling Y, Chang W, Xie G, et al. (2016) Monoacylglycerol lipase inhibitor JZL184 regulates apoptosis and migration of colorectal cancer cells. Mol Med Rep 13(3): 2850-2856.

52.Zhang X, Thayer SA (2018) Monoacylglycerol lipase inhibitor JZL184 prevents HIV-1 gp120-induced synapse loss by altering endocannabinoid signaling. Neuropharmacology 128: 269-281.
53. Cao Z, Mulvihill MM, Mukhopadhyay P, Xu H, Erdelyi K, et al. (2013) Monoacylglycerol lipase controls endocannabinoid and eicosanoid signaling and hepatic injury in mice. Gastroenterology 144(4): 808817.e15

54. Liu Z, Wang Y, Zhao H, Zheng Q Xiao L, et al. (2014) CB2 receptor activation ameliorates the proinflammatory activity in acute lung injury induced by paraquat. Biomed Res Int. 2014: 971750.

55. Li Q, Wang F, Zhang YM, Zhou JJ, Zhang Y (2013) Activation of cannabinoid type 2 receptor by JWH133 protects heart against ischemia/reperfusion-induced apoptosis. Cell Physiol Biochem 31(45): 693-702

Your next submission with Juniper Publishers will reach you the below assets

- Quality Editorial service

- Swift Peer Review

- Reprints availability

- E-prints Service

- Manuscript Podcast for convenient understanding

- Global attainment for your research

- Manuscript accessibility in different formats (Pdf, E-pub, Full Text, Audio)

- Unceasing customer service

Track the below URL for one-step submission https://juniperpublishers.com/online-submission.php 